\title{
Burden of disease and cost of chronic hepatitis C virus infection in Canada
}

\author{
Robert P Myers MD MSc${ }^{1}$, Mel Krajden MD², Marc Bilodeau MD³, Kelly Kaita MD4, Paul Marotta MD ${ }^{5}$, \\ Kevork Peltekian $\mathrm{MD}^{6}$, Alnoor Ramji MD${ }^{7}$, Chris Estes $\mathrm{MPH}^{8}$, Homie Razavi PhD ${ }^{8}$, Morris Sherman $\mathrm{MD}^{9}$
}

\begin{abstract}
RP Myers, M Krajden, M Bilodeau, et al. Burden of disease and cost of chronic hepatitis $\mathrm{C}$ virus infection in Canada. Can J Gastroenterol Hepatol 2014;28(5):243-250.
\end{abstract}

BACKGROUND: Chronic infection with hepatitis $\mathrm{C}$ virus (HCV) is a major cause of cirrhosis, hepatocellular carcinoma and liver transplantation.

OBJECTIVE: To estimate the burden of HCV-related disease and costs from a Canadian perspective.

METHODS: Using a system dynamic framework, the authors quantified the HCV-infected population, disease progression and costs in Canada between 1950 and 2035. Specifically, 36 hypothetical, ageand sex-defined cohorts were tracked to define HCV prevalence, complications and direct medical costs (excluding the cost of antivirals). Model assumptions and costs were extracted from the literature with an emphasis on Canadian data. No incremental increase in antiviral treatment over current levels was assumed, despite the future availability of potent antivirals.

RESULTS: The estimated prevalence of viremic hepatitis C cases peaked in 2003 at 260,000 individuals (uncertainty interval 192,460 to 319,880 ), reached 251,990 (uncertainty interval 177,890 to 314,800 ) by 2013 and is expected to decline to 188,190 (uncertainty interval 124,330 to 247,200 ) in 2035 . However, the prevalence of advanced liver disease is increasing. The peak annual number of patients with compensated cirrhosis $(n=36,210)$, decompensated cirrhosis $(n=3380)$, hepatocellular carcinoma $(n=2220)$ and liver-related deaths $(n=1880)$ are expected to occur between 2031 and 2035. During this interval, an estimated 32,460 HCV-infected individuals will die of liver-related causes. Total health care costs associated with HCV (excluding treatment) are expected to increase by $60 \%$ from 2013 until the peak in 2032, with the majority attributable to cirrhosis and its complications ( $81 \%$ in 2032 versus $56 \%$ in 2013). The lifetime cost for an individual with HCV infection in 2013 was estimated to be $\$ 64,694$.

CONCLUSIONS: Although the prevalence of HCV in Canada is decreasing, cases of advanced liver disease and health care costs continue to rise. These results will facilitate disease forecasting, resource planning and the development of rational management strategies for HCV in Canada.

Key Words: Cirrhosis; Hepatitis C; Hepatocellular carcinoma; Mortality; Outcomes; Treatment

$\mathrm{C}$ hronic hepatitis $\mathrm{C}$ virus (HCV) infection is an important public health problem, with an estimated 170 million prevalent cases, three to four million newly infected cases annually and a mean seroprevalence of approximately $3 \%$ worldwide (1). Although the prevalence of HCV in Canada is unknown, the Public Health Agency of Canada (PHAC) has reported that $0.96 \%$ of the population was antiHCV positive in 2011 (2). Whereas the peak prevalence is in young and middle-age ( 30 to 59 years) individuals, the peak age for incident

\section{Le fardeau et le coût de l'infection chronique par le virus de l'hépatite $\mathrm{C}$ au Canada}

HISTORIQUE : L'infection chronique par le virus de l'hépatite C (VHC) est une cause importante de cirrhose, de carcinome hépatocellulaire et de transplantation hépatique.

OBJECTIF : Évaluer le fardeau et le coût des maladies liées au VIH dans une perspective canadienne.

MÉTHODOLOGIE : Dans un cadre dynamique, les auteurs ont quantifié la population infectée par le VHC, ainsi que l'évolution et le coût de la maladie au Canada entre 1950 et 2035. Plus précisément, 36 cohortes hypothétiques, définies en fonction de l'âge et du sexe, ont été suivies pour définir la prévalence, les complications et les coûts médicaux directs (à l'exception du coût des antiviraux) du VHC. Les hypothèses et les coûts des modèles ont été tirés des publications, particulièrement celles d'origine canadienne. Aucune augmentation incrémentielle du traitement aux antiviraux n'a été présumée par rapport aux taux actuels, malgré l'accessibilité potentielle à de futurs antiviraux.

RÉSULTATS : La prévalence estimative des cas d'hépatite C virémique a atteint un sommet en 2003, avec 260000 individus (intervalle d'incertitude de 192460 à 319 880). Elle a atteint 251990 (intervalle d'incertitude de 177890 à 314800 ) en 2013 et devrait reculer à 188190 (intervalle d'incertitude de 124330 à 247 200) en 2035. Cependant, la prévalence de maladie hépatique avancée augmente. Le nombre annuel maximal de patients ayant une cirrhose compensée ( $n=36$ 210), une cirrhose décompensée $(n=3$ 380), un carcinome hépatocellulaire $(\mathrm{n}=2220)$ et décédés à cause de problèmes hépatiques $(n=1880)$ devrait être atteint entre 2031 et 2035. Pendant cet intervalle, on estime que 32460 personnes infectées par le VHC mourront d'une cause liée à un problème hépatique. Les coûts de santé totaux associés au VHC (à l'exclusion du traitement) devraient augmenter de $60 \%$ entre 2013 et le sommet de 2032, en majorité à cause de la cirrhose et de ses complications (81 \% en 2032, par rapport à $56 \%$ en 2013). En 2013, le coût à vie d'une personne atteinte d'une infection par le VHC était évalué à 64694 \$.

CONCLUSIONS : Même si la prévalence de VHC diminue au Canada, les cas de maladie hépatique avancée et les coûts des soins continuent d'augmenter. Ces résultats contribueront à la prévision des maladies, à la planification des ressources et à l'élaboration de stratégies rationnelles de prise en charge du VHC au Canada.

or acute hepatitis $\mathrm{C}$, which mainly results from injection drug use (IDU) (3), is approximately 20 years younger (4).

Modelling studies and anecdotal reports suggest that the burden of $\mathrm{HCV}$ in Canada is increasing $(3,5)$. For example, PHAC estimated that cases of HCV-related end-stage liver disease, hepatocellular carcinoma (HCC), liver transplantation and deaths would increase by approximately 20\% to 80\% between 1997 and 2027 (3). However, the results of this and other modelling studies may underestimate the true

\footnotetext{
${ }^{1}$ Liver Unit, Division of Gastroenterology and Hepatology, Department of Medicine, University of Calgary, Calgary, Alberta; ${ }^{2} \mathrm{BC}$ Centre for Disease Control, Vancouver, British Columbia; ${ }^{3}$ University of Montreal, Montreal, Quebec; ${ }^{4}$ University of Manitoba, Winnipeg, Manitoba; ${ }^{5}$ Western

University, London, Ontario; ${ }^{6}$ Dalhousie University, Halifax, Nova Scotia; ${ }^{7}$ University of British Columbia, Vancouver, British Columbia; ${ }^{8}$ Center for Disease Analysis, Louisville, Colorado, USA; ${ }^{9}$ University of Toronto, Toronto, Ontario

Correspondence: Dr Robert P Myers, Liver Unit, University of Calgary, 6D22, Teaching, Research and Wellness Building, 3280 Hospital Drive

Northwest, Calgary, Alberta T2N 426. Telephone 403-592-5049, fax 403-592-5090, e-mail rpmyers@ucalgary.ca
}

Received for publication March 6, 2014. Accepted April 2, 2014 


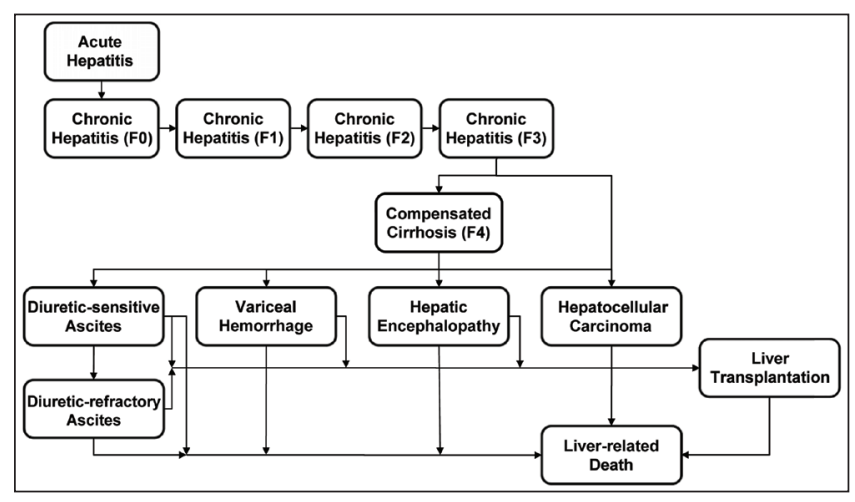

Figure 1) Schematic of hepatitis $C$ disease progression model

TABLE 1

Model inputs and 2013 estimates

\begin{tabular}{|c|c|c|c|}
\hline & Historical & Year & $\begin{array}{c}2013 \\
\text { Estimate }\end{array}$ \\
\hline Anti-HCV+ cases* & $\begin{array}{c}329,760 \\
(209,530-460,280)\end{array}$ & 2011 & 322,480 \\
\hline Anti-HCV prevalence* & $0.9(0.6-1.3)$ & & $0.7 \%$ \\
\hline Total viremic cases* & $\begin{array}{c}253,910 \\
(161,340-354,420)\end{array}$ & 2011 & 248,310 \\
\hline Viremic prevalence, \% & $0.7(0.5-1.0)$ & & 0.5 \\
\hline Proportion viremic, \% & 77.0 & & 77.0 \\
\hline Diagnosed, viremic cases & 176,400 & 2013 & 176,400 \\
\hline $\begin{array}{l}\text { Proportion of viremic cases } \\
\text { diagnosed, \% }\end{array}$ & 70 & & 70 \\
\hline $\begin{array}{l}\text { Annual number of newly } \\
\text { diagnosed cases, } n\end{array}$ & 7640 & 2011 & 7640 \\
\hline New infections & & & 5570 \\
\hline New infection rate, per 100,000 & & & 15.9 \\
\hline Treated cases, annually, n (\%) & & & $3600(1.4)$ \\
\hline \multicolumn{4}{|l|}{ HCV risk factors } \\
\hline Active IDUs with $\mathrm{HCV}, \mathrm{n}$ & & & 54,630 \\
\hline $\begin{array}{l}\text { Proportion of prevalent cases } \\
\text { due to active IDU, \% }\end{array}$ & & & 22 \\
\hline $\begin{array}{l}\text { Number of previously } \\
\text { transfused cases with HCV }\end{array}$ & & & 27,310 \\
\hline $\begin{array}{l}\text { Proportion of prevalent cases } \\
\text { due to previous blood } \\
\text { transfusion, } \%\end{array}$ & & & 11 \\
\hline \multicolumn{4}{|l|}{ HCV genotype, \% } \\
\hline $1 \mathrm{a}$ & & & 36.5 \\
\hline $1 b$ & & & 21.5 \\
\hline 1 (other) & & & 6.1 \\
\hline 2 & & & 14.1 \\
\hline 3 & & & 20.2 \\
\hline 4 & & & 0.3 \\
\hline 5 & & & 0 \\
\hline 6 & & & 0 \\
\hline Other & & & 1.3 \\
\hline
\end{tabular}

${ }^{*}$ Data presented as \% (uncertainty interval). HCV Hepatitis C virus; IDU Injection drug use

burden of HCV. According to administrative data from Calgary, Alberta, liver-related hospitalizations, hospital costs and mortality rose fourfold between 1994 and 2004 (6). This apparent discrepancy between modelled and actual outcomes may relate, in part, to study methodology. Typically, Markov models have been used in which a homogenous cohort of HCV-infected individuals is introduced and the model is used to track their progression over time. However, the predictability of these models is highly sensitive to the number of age and

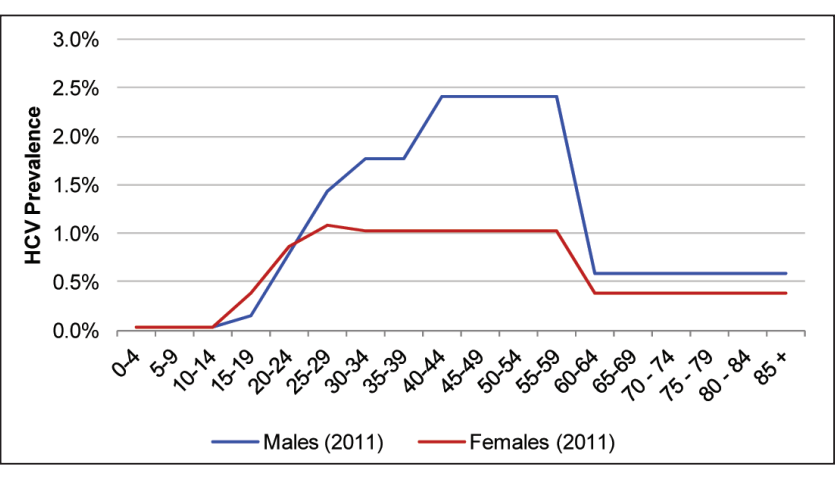

Figure 2) Age and sex distribution of anti-hepatitis $\mathrm{C}$ virus ( $\mathrm{HCV}$ )-positive cases in Canada, 2011

sex cohorts used due to differences in HCV incidence and mortality (among other factors) across the cohorts (7). In the current study, we aimed to create a disease progression model that was more refined. Specifically, we modelled 36 age- and sex-defined cohorts to provide maximum flexibility in changing inputs (eg, incidence, treatment and cure rate, and mortality). Our objective was to describe the future burden of disease and cost of HCV infection in Canada, assuming there is no incremental increase in treatment as the result of new therapies. Although more effective and better tolerated antivirals are on the horizon, our goal was to gain a better understanding of baseline estimates before the widespread use of these newer agents. Future analyses will model the impact of different management strategies aimed at reducing disease burden and costs (eg, increased treatment uptake, improved cure rates and enhanced case identification).

System dynamic model

\section{METHODS}

As previously described (8), a system dynamic modelling framework was used to construct a model in Excel (Microsoft Corporation, USA) to quantify the HCV-infected population, disease progression and associated costs in Canada from 1950 to 2035. The model was constructed for sensitivity and Monte Carlo analysis using Crystal Ball, an Excel add-in by Oracle (USA), and beta-PERT distributions were used for all uncertain inputs. A systematic review of the literature was conducted to identify studies reporting relevant Canadian data for incorporation into the model. Indexed articles were found by searching PubMed and Embase, and through consultation with Canadian HCV experts. Ranges were used to capture uncertainty in inputs with wider ranges implying greater uncertainty.

Progression from acute HCV infection through disease states encompassing all fibrosis stages and sequelae of chronic HCV infection was modelled as shown in Figure 1. The total numbers of cases at each disease stage were tracked according to age cohorts and sex. Thirty-six five-year age cohorts were used through 84 years of age; individuals $\geq 85$ years of age were treated as one cohort. Each year, onefifth of the population in each age group, except for $\geq 85$ years, was moved to the next age cohort to simulate aging after accounting for mortality (see below). Background Canadian population data, obtained from the United Nations population database (9), were organized according to sex, five-year age groups and year (1950 to 2035).

\section{HCV prevalent population}

For anti-HCV prevalence, the rate reported by PHAC for $2011(0.96 \%$ [uncertainty interval $0.61 \%$ to $1.34 \%$ ]) was used (Table 1) (2). The age and sex distribution of the prevalent population was based on notification data from PHAC (10) (Figure 2). An estimated $77 \%$ of these cases were assumed to be viremic (11), with a genotype distribution based on data collected from Canadian patients between 1998 and 2004 (Table 1) (12). Viremic prevalence in 2011 was estimated to be $0.74 \%$ (uncertainty interval $0.47 \%$ to $1.0 \%$ ). 
There was considerable variation in the reported data regarding the proportion of infected patients diagnosed with $\mathrm{HCV}$ and the number aware of their infection. PHAC estimated that $79 \%$ of $\mathrm{HCV}$ positive individuals were diagnosed in 2007 (3), while national household surveys conducted from 2007 to 2011 found that 30\% of anti-HCV-positive individuals were aware of their infection (13). Based on expert consensus, it was estimated that $70 \%$ of the infected population was diagnosed in 2013. The newly diagnosed population was estimated based on the number of notifications from the most recent year of data reported by PHAC (2011): there were 9923 notifications (10) and $77 \%$ were assumed to be viremic (11). It was estimated that 176,400 viremic individuals were diagnosed in Canada in 2013 and 7641 viremic individuals were newly diagnosed.

\section{New HCV cases}

The number of PHAC-reported HCV case notifications peaked in 1998 at 19,379 (14). In the model, the annual magnitude of new cases, including the age and sex distribution of these cases, was back calculated to reach the estimated prevalent population value in 2011 (2), using Frontline Solver for Excel. Proportional changes in incidence according to year were derived from historical incidence estimates from a PHAC analysis (3). In 2013, 5570 new HCV cases were estimated to have occurred.

\section{Antiviral treatment}

The state of HCV care in Canada generally involves treatment of individuals with at least moderate (stage 2 to 4 ) liver fibrosis. In the model, it was assumed that all treated patients were between 18 and 64 years of age and had at least moderate fibrosis, and that $60 \%$ of all patients were medically eligible or willing to undergo antiviral therapy. According to the literature $(15,16)$, approximately $40 \%$ to $60 \%$ of HCV patients are eligible for treatment. The definition of eligibility included contraindications to antiviral therapies (eg, severe cardiorespiratory disease or uncontrolled psychiatric conditions) as well as patient preference.

The historical treated population from 2001 to 2003 was estimated to be 5000 cases annually. During this period, sustained virological response (SVR) rates of 30\% (genotype 1 [G1]), 66\% (G2 and G3) and $40 \%$ (G4) were applied assuming the standard of care for all genotypes included interferon and ribavirin therapy. The treated population in 2004 to 2012 was calculated based on data for standard units of peginterferon sold in Canada as reported by IMS Health (17), with multipliers to account for under-reporting and compliance/persistence (85\%). In this calculation, the Canadian genotype distribution (12) was used to estimate the average number of weeks of treatment per patient. SVR rates were the same as during 2001 to 2003, except for G1, for which SVR rate increased to $40 \%$ with the use of peginterferon-based therapy. Beginning in 2013, it was estimated that 3600 cases were treated annually. Historically, more patients were treated but deferral of treatment has recently increased due to the prospect of more effective therapies. It was assumed that SVR rates for patients with G1 would increase to $60 \%$ with triple therapy including a first-generation protease inhibitor (boceprevir or telaprevir) (18). Although second-generation, direct-acting antivirals with higher rates of treatment success were approved in Canada in late 2013, a status quo model was assumed, with no incremental increase in treatment as the result of these new therapies. Similarly, the higher SVR rates and costs of these therapies were specifically excluded to establish a baseline for future comparisons. This approach, however, will lead to higher projections of advanced liver disease compared with the real world.

\section{Transition probabilities}

Age- and sex-specific transition probabilities were used to progress patients annually through each disease state, as described previously (8). A spontaneous $\mathrm{HCV}$ clearance rate of $23 \%$ among new cases was assumed (19). For cases without spontaneous clearance, disease progression was simulated by multiplying the total number of cases at a particular stage of the disease by a progression rate to the next stages. The rates were gathered from previous studies $(8,20-27)$ or calculated (Table 2$)$.

\section{Liver transplantation and mortality}

The historical number of liver transplants completed annually in Canada was available through the Canadian transplant registry (28), along with the percentage of transplants attributable to chronic HCV infection (29). In 2011, there were 482 liver transplants performed in Canada. Of these, $33 \%$ were estimated to be HCV-related. Data from United States sources were used to estimate mortality among liver transplant recipients $(30,31)$. Estimates of future liver transplants do not consider organ availability and include all cases progressing to liver transplant eligibility.

Background mortality rates according to year, age group and sex were extracted from the Berkeley Human Mortality database (32) and excess mortality related to IDU and transfusion were estimated. Specifically, a standardized mortality ratio (SMR) of 10.0 (uncertainty interval 9.5 to 29.9) for individuals between 15 and 44 years of age was applied for the population infected via active IDU (33-38) (an estimated $22 \%$ of the prevalent population) (3). In 2007, it was estimated that $11.0 \%$ of the prevalent population was infected through transfusion (3) and that this will decline to $0 \%$ by 2030 . For these individuals, an SMR of 2.1 (uncertainty interval 1.3 to 17.6) was applied for all age groups (39).

\section{Costs}

To quantify costs associated with chronic HCV infection, cost data collected through Canadian studies were applied (Table 3) (40-42). The health care costs among noncirrhotic patients (F0 to F3 fibrosis) were adjusted for the proportion not under care, which varied from $39 \%$ (F0) to $24 \%$ (F3). Historical cost data were inflated through 2013 using the health care component of the Canadian consumer price index (43), and no future inflation was assumed. The range of low and high costs were calculated based on the ratios between base and high/low costs from United States data (8), except where Canadian data were available. The estimated future lifetime cost of an HCV-infected male 35 to 39 years of age in 2013 was calculated by introducing 100 viremic incident cases in 2013 in each disease state and using the model to track the progression of these cases and costs over time. The annual health care costs for all sequelae and all years were summed and divided by 100 to calculate the estimated individual lifetime cost.

\section{RESULTS}

Prevalence of chronic hepatitis $\mathrm{C}$ and complications

According to the model, the prevalence of HCV in Canada peaked in 2003 at 260,000 viremic individuals (Figure 3). In 2013, a total of 251,990 (uncertainty interval 177,890 to 314,800 ) viremic cases was estimated, with the highest number of cases in the 40- to 54-year age groups (Figure 4). By 2035, the chronically infected population is projected to decrease to 188,190 (uncertainty interval 124,330 to 247,200 ) cases, a $25 \%$ decline from the peak in 2003 . However, cases of compensated and decompensated cirrhosis are expected to peak in 2031 at 36,210 and 3380 cases, respectively (Figure 5A). The number of individuals with HCC caused by HCV infection will increase to 2220 cases in 2035 before starting to decline. HCV-related mortality will peak in 2034, when annual liver-related deaths are estimated to reach 1880 cases. Between 2013 and 2035, the authors estimate that $32,460 \mathrm{HCV}$-infected individuals will die of liver-related causes (mean age at death, 67.8 years). In 2013, 8.7\% of the chronically infected population is expected to experience cirrhosis or more advanced HCV-related sequelae, whereas this proportion will increase to $23 \%$ by 2035 (Figure 5B). Compared with 2013, cases of compensated cirrhosis, decompensated cirrhosis, HCC and liver-related deaths are expected to increase $89 \%, 80 \%, 205 \%$ and $160 \%$, respectively, by 2035. 
TABLE 2

Hepatitis $C$ disease progression rates used in the model

Back-calculated progression rates: Males

\begin{tabular}{|c|c|c|c|c|c|c|c|c|c|c|c|c|c|c|c|c|c|c|}
\hline & \multicolumn{18}{|c|}{ Age cohort, years } \\
\hline & $0-4$ & $5-9$ & $10-14$ & 15-19 & $20-24$ & $25-29$ & $30-34$ & $35-39$ & $40-44$ & $45-49$ & $50-54$ & $55-59$ & $60-64$ & 65-69 & $70-74$ & $75-79$ & $80-84$ & $\geq 85$ \\
\hline F1 to F2 & 3.8 & 3.8 & 4.7 & 4.7 & 3.8 & 3.8 & 2.7 & 2.7 & 10.1 & 10.1 & 12.4 & 12.4 & 14.1 & 14.1 & 15.8 & 15.8 & 13.0 & 13.0 \\
\hline F3 to cirrhosis & 0.0 & 0.0 & 0.8 & 0.8 & 2.5 & 2.5 & 5.7 & 5.7 & 8.8 & 8.8 & 4.8 & 4.8 & 9.9 & 9.9 & 19.1 & 19.1 & 19.1 & 19.1 \\
\hline $\mathrm{F} 3$ to $\mathrm{HCC}$ & 0.0 & 0.0 & 0.0 & 0.0 & 0.0 & 0.0 & 0.0 & 0.0 & 0.1 & 0.1 & 0.1 & 0.1 & 0.2 & 0.2 & 0.3 & 0.3 & 0.3 & 0.3 \\
\hline Cirrhosis to HCC & 0.3 & 0.3 & 0.3 & 0.3 & 0.3 & 0.3 & 0.5 & 0.5 & 0.9 & 0.9 & 1.4 & 1.4 & 2.4 & 2.4 & 3.9 & 3.9 & 3.9 & 3.9 \\
\hline
\end{tabular}

\begin{tabular}{lllllllllllllllllll}
\hline & \multicolumn{110}{c}{ Age cohort, years } \\
\cline { 2 - 7 } & $\mathbf{0 - 4}$ & $\mathbf{5 - 9}$ & $\mathbf{1 0 - 1 4}$ & $\mathbf{1 5 - 1 9}$ & $\mathbf{2 0 - 2 4}$ & $\mathbf{2 5 - 2 9}$ & $\mathbf{3 0 - 3 4}$ & $\mathbf{3 5 - 3 9}$ & $\mathbf{4 0 - 4 4}$ & $\mathbf{4 5 - 4 9}$ & $\mathbf{5 0 - 5 4}$ & $\mathbf{5 5 - 5 9}$ & $\mathbf{6 0 - 6 4}$ & $\mathbf{6 5 - 6 9}$ & $\mathbf{7 0 - 7 4}$ & $\mathbf{7 5 - 7 9}$ & $\mathbf{8 0 - 8 4}$ & $\mathbf{2 8 5}$ \\
\hline F0 to F1 & 4.4 & 4.4 & 5.4 & 5.4 & 4.3 & 4.3 & 3.1 & 3.1 & 11.6 & 11.6 & 14.3 & 14.3 & 16.2 & 16.2 & 18.2 & 18.2 & 14.9 & 14.9 \\
F1 to F2 & 3.2 & 3.2 & 3.9 & 3.9 & 3.1 & 3.1 & 2.3 & 2.3 & 8.4 & 8.4 & 10.4 & 10.4 & 11.7 & 11.7 & 13.2 & 13.2 & 10.8 & 10.8 \\
F2 to F3 & 4.5 & 4.5 & 5.5 & 5.5 & 4.4 & 4.4 & 3.2 & 3.2 & 11.9 & 11.9 & 14.6 & 14.6 & 16.6 & 16.6 & 18.6 & 18.6 & 15.3 & 15.3 \\
F3 to cirrhosis & 0.0 & 0.0 & 0.6 & 0.6 & 2.1 & 2.1 & 4.7 & 4.7 & 7.4 & 7.4 & 4.0 & 4.0 & 8.3 & 8.3 & 15.9 & 15.9 & 15.9 & 15.9 \\
F3 to HCC & 0.0 & 0.0 & 0.0 & 0.0 & 0.0 & 0.0 & 0.0 & 0.0 & 0.0 & 0.0 & 0.1 & 0.1 & 0.1 & 0.1 & 0.2 & 0.2 & 0.2 & 0.2 \\
Cirrhosis to HCC & 0.3 & 0.3 & 0.3 & 0.3 & 0.3 & 0.3 & 0.4 & 0.4 & 0.7 & 0.7 & 1.2 & 1.2 & 2.0 & 2.0 & 3.3 & 3.3 & 3.3 & 3.3 \\
\hline
\end{tabular}

Data presented as \%. F Fibrosis stage; HCC Hepatocellular carcinoma

Disease progression

Reported progression rates, \%

Diuretic-sensitive ascites to diuretic refractory ascites

Diuretic-sensitive ascites to liver-related death

Variceal hemorrhage to liver-related death (first year)

Variceal hemorrhage to liver-related death (subsequent years)

Hepatic encephalopathy to liver-related death (first year)

Hepatic encephalopathy to liver-related death (subsequent years)

Diuretic-refractory ascites to liver-related death

Hepatocellular carcinoma to liver-related death (first year)

Hepatocellular carcinoma to liver-related death (subsequent years)

Liver transplant to liver-related death (first year)

Liver transplant to liver-related death (subsequent years)

\begin{tabular}{cc} 
(uncertainty interval) & Reference(s) \\
\hline $6.7(4.0-9.4)$ & $8,20-27$ \\
$11.0(7.7-14.3)$ & $8,20-27$ \\
$40.0(33.4-46.6)$ & $8,20-27$ \\
$13.0(8.5-17.5)$ & $8,20-27$ \\
$68.0(65.9-70.1)$ & $8,20-27$ \\
$40.0(37.8-42.2)$ & $8,20-27$ \\
$33.0(28.0-38.0)$ & $8,20-27$ \\
$70.7(43-77.0)$ & 26,58 \\
$16.2(11-23.0)$ & 58 \\
$33.1-10.7(2.8-0.4)$ & 30,31 \\
$3.9-4.8(7.6-1.0)$ & 30,31
\end{tabular}

\section{TABLE 3}

Incremental costs of hepatitis $C$ virus infection according to disease stage used in the model

\begin{tabular}{|c|c|c|c|c|}
\hline Disease stage & Annual cost, \$CAD & Reference & Range, \$CAD & Reference(s) \\
\hline Hepatitis $\mathrm{C}$ virus (F0 to $\mathrm{F} 3$ ) & 383 & 40 & $215-551$ & 8 \\
\hline Compensated cirrhosis (F4) & 808 & 40 & $545-1,070$ & 8 \\
\hline Diuretic-sensitive ascites & 5,632 & 40 & $506-5,979$ & 8 \\
\hline Diuretic-refractory ascites & 16,762 & 40 & $15,731-17,793$ & 8 \\
\hline Variceal hemorrhage (first year) & 20,096 & 40 & $18,860-21,332$ & 8 \\
\hline Variceal hemorrhage (subsequent years) & 20,096 & 40 & $3,689-21,332$ & 8 \\
\hline Hepatic encephalopathy (first year) & 8,790 & 40 & $1,614-9,331$ & 8 \\
\hline Hepatic encephalopathy (subsequent years) & 8,790 & 40 & $1,227-9,331$ & 8 \\
\hline Hepatocellular carcinoma & 16,049 & 59 & $14,404-17,694$ & 8 \\
\hline Liver transplant (first year) & 117,284 & 42 & $63,664-170,905$ & 40,42 \\
\hline Liver transplant (subsequent years) & 40,164 & 40 & $32,819-47,509$ & 8 \\
\hline
\end{tabular}

\section{F Fibrosis stage}

Costs associated with chronic hepatitis $\mathrm{C}$

Total cost is projected to increase by $60 \%$ from $\$ 161.4$ million (uncertainty interval $\$ 85.4$ million to $\$ 251.5$ million) in 2013 to $\$ 258.4$ million (uncertainty interval $\$ 121.4$ million to $\$ 394.6$ million) at the peak in 2032. In 2013, the authors estimated that $56 \%$ of total costs were attributable to cirrhosis and more advanced liver disease. By 2032 , this proportion is expected to rise to $81 \%$. The majority of peak cost will be attributable to cases of decompensated cirrhosis, including those who undergo liver transplantation $(55 \%$ in 2032 versus $39 \%$ in 2013), compensated cirrhosis (12\% versus $10 \%$ ) and HCC (14\% versus $7 \%$ ). For a hypothetical male 35 to 39 years of age with HCV infection in 2013, the estimated lifetime cost is $\$ 64,694$ in 2013
Canadian dollars. However, the estimated lifetime costs of HCV vary substantially according to disease state (Table 4). Specifically, lifetime future costs ranged from $\$ 51,946$ for a patient with no fibrosis (F0) in 2013 up to $\$ 327,608$ for a patient requiring liver transplantation in 2013. Of note, the future lifetime cost for prevalent HCC cases $(\$ 42,376)$ was estimated to be relatively low due to a high mortality rate from progressive liver-related disease in those infected.

\section{DISCUSSION}

Using a novel modelling approach, we have demonstrated that the prevalence of $\mathrm{HCV}$ infection in Canada will decrease, while the burden of advanced liver disease and associated costs will continue to 


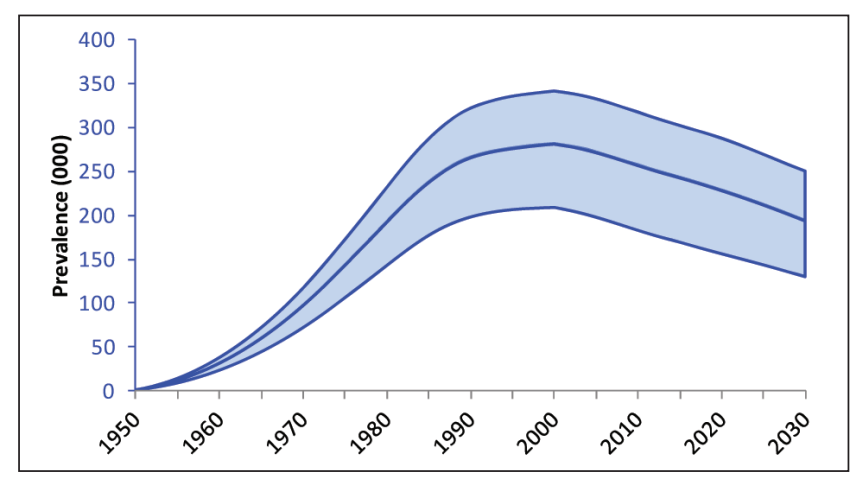

Figure 3) Total number of viremic hepatitis $C$ cases (with uncertainty intervals) according to year, 1950 to 2035

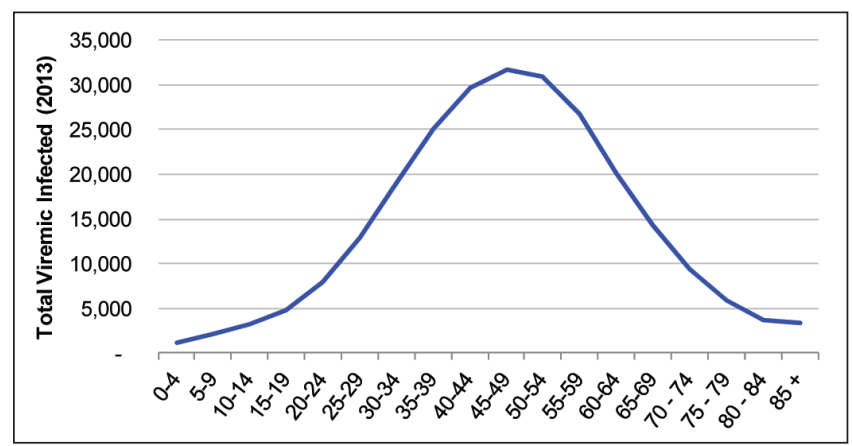

Figure 4) Total number of viremic hepatitis $C$ cases cases according to age, 2013

grow over the next 20 years. Already, there is evidence in Ontario that the disease burden from HCV exceeds that of all other infectious diseases (44); these data are likely generalizable to the remainder of the country. Our analysis predicted that HCV prevalence in Canada peaked in 2003 at 260,000 viremic cases and affected 251,990 individuals in 2013. At current levels of antiviral treatment utilization and efficacy, the prevalence in Canada is expected to decline to 188,190 cases by 2035 . Although this $28 \%$ decline compared with the peak is encouraging, it is partly attributable to HCVrelated mortality. We project that without increased treatment access and uptake, approximately 32,500 HCV-infected individuals will die of liver-related causes between 2013 and 2035. Moreover, premature mortality attributable to HCV infection is substantial, as emphasized by the disparity in the mean age at death of the cohort (68 years) compared with average life expectancy in Canada (81 years) (32).

The results of our analysis also show that $>70 \%$ of the infected population in Canada was born between 1944 and 1978 (Figure 4). This figure is relevant given recent recommendations by the Canadian Liver Foundation advocating one time, birth-cohort screening for HCV among Canadians born between 1945 and 1975 (45,46). Based on our analysis, this approach would identify the majority of HCVinfected cases in Canada, including those most likely to develop liverrelated complications. Birth-cohort HCV screening has also been recommended by the Centers for Disease Control and Prevention (Georgia, USA) based on data showing that $75 \%$ of prevalent cases in the United States were born between 1945 and 1965. To date, the uptake and impact of these recommendations have not been confirmed.

As shown in Figure 5A, the proportion of patients with advanced HCV-related liver disease will increase between 2013 and 2035. This phenomenon is due to aging of the infected population and resultant liver fibrosis progression. The incidence of decompensated cirrhosis, HCC and liver transplantation are expected to peak between 2031 and 2035. Figure 5B, which illustrates the proportions of the prevalent

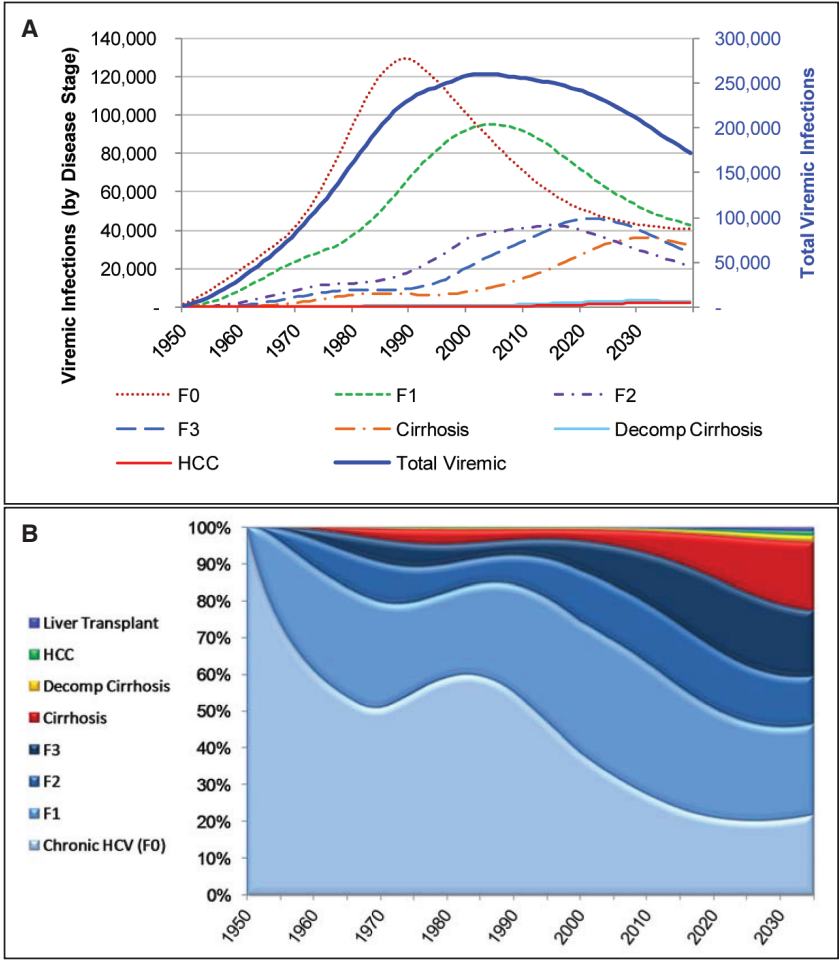

Figure 5) A Number of viremic hepatitis $\mathrm{C}(\mathrm{HCV})$ cases, in total and according to disease stage. B Proportion of all viremic HCV cases according to disease stage, 1950 to 2035. Decomp Decompensated; F Fibrosis stage; HCC Hepatocellular carcinoma

\section{TABLE 4}

\section{Estimated future lifetime cost according to disease state for men 35 to 39 years of age with hepatitis $C$ virus} infection in 2013

\begin{tabular}{lc}
\hline & Cost in 2013, \$CAD \\
\hline Chronic hepatitis C virus infection (F0) & 51,946 \\
F1 & 62,184 \\
F2 & 79,926 \\
F3 & 100,589 \\
Compensated cirrhosis (F4) & 133,575 \\
Diuretic-sensitive ascites & 196,770 \\
Diuretic-refractory ascites & 139,330 \\
Variceal hemorrhage & 189,398 \\
Hepatic encephalopathy & 133,505 \\
Hepatocellular carcinoma & 42,376 \\
Liver transplant & 327,608 \\
\hline FFibrosis stage
\end{tabular}

F Fibrosis stage

HCV population within each disease state, is informative. First, most individuals with $\mathrm{HCV}(>75 \%)$ at any given point in time have noncirrhotic disease (ie, stage 0 to 3 fibrosis). This represents an ideal opportunity to intervene with antiviral therapy to prevent progression to more advanced stages when treatment becomes less effective and less well tolerated, at least with interferon-based treatments. Second, a smaller proportion of the population will progress to develop HCC ( $<1 \%$ of prevalent cases). Third, nearly $23 \%$ of the chronically infected population is expected to experience cirrhosis or more advanced HCV-related sequelae in 2035 compared with only $9 \%$ in 2013. These increases ( $80 \%$ for decompensated cirrhosis, $205 \%$ for HCC and $160 \%$ for liver-related mortality) are substantially greater than those projected by Remis (3) between 2012 and 2027 (-1.2\% for decompensated cirrhosis, $4.8 \%$ for HCC and $14.8 \%$ for liver-related 
mortality) (3). Similarly, our projected number of cases with HCVrelated complications in 2035 are significantly higher. For example, in 2027, Remis (3) estimated 483 cases of decompensated cirrhosis (versus 3250 in our study), 325 cases of HCC (versus 1910 in our study) and 613 liver-related deaths (versus 1665 in our study). Finally, we estimate that approximately 35,000 individuals will have compensated, HCV-related cirrhosis in 2035. If left undiagnosed and/or untreated, these patients face a significant risk of death due to complications of $\mathrm{HCV}$ in the coming years.

We estimated that the total health care costs associated with chronic HCV infection in Canada will increase by $60 \%$ between 2013 and the peak in 2032. A key observation was that peak health care costs lag behind peak prevalence by nearly three decades due to the time required for infected cases to progress to more advanced disease stages, which are more costly to manage. In that regard, the majority of estimated costs (approximately 56\%) were attributable to the treatment of HCV-related cirrhosis and its complications. In 2013, decompensated cirrhosis accounted for 39\% of estimated costs (including those attributable to transplantation), and by 2032 it accounted for $55 \%$. This was followed by compensated cirrhosis (10\% of 2013 and $12 \%$ of 2032 total cost) and HCC (7\% of 2013 and $14 \%$ of 2032 total cost). In 2013, the prevalence of decompensated cirrhosis was oneseventh that of compensated cirrhosis, but the annual cost was fourtimes higher, emphasizing the need for early diagnosis and treatment.

On a per-patient basis, we estimated the average lifetime cost of HCV to be $\$ 64,694$, much higher than a recent United States report describing an average cost of $\$ 19,660$ per patient in 2002 to 2010 (47). Not surprisingly, the estimated lifetime cost of an individual infected with HCV varied substantially depending on disease stage (Table 4), with the highest per-patient costs attributable to liver transplantation (approximately $\$ 328,000$ ). Previous analyses of cost according to the age at HCV infection have also demonstrated a link between life expectancy and health care costs (8). Individuals infected in the 1950s were expected to have lower lifetime costs due to lower life expectancy and medical costs, while newly infected individuals are expected to cost the health care system more due to their longer life expectancy and higher medical costs. This highlights the importance of efforts aimed at preventing acute HCV infections (eg, by providing harm reduction, safer injection facilities or potentially using treatment of active injection drug users to prevent onward HCV transmission) $(48,49)$ as a means of limiting future health care expenditures.

A strength of the present analysis was the availability of national estimates for HCV prevalence in Canada. However, these data have limitations, particularly with respect to the number of diagnosed cases that have been reported to the PHAC Notifiable Disease Surveillance System. Diagnosed cases may be double-counted and high-risk groups may be under-represented, which could underestimate both the prevalence as well as proportion of undiagnosed individuals in Canada (45). In an attempt to address this uncertainty, the Canadian Health Measures Survey, a stratified serosurvey of viral hepatitis across Canada, recently reported an HCV seroprevalence of $0.5 \%$ with $30.5 \%$ of individuals being aware of their infection (13). However, this survey undersampled high-risk communities including injection drug users, prisoners, the homeless and Aboriginals. Due to this limitation, the Canadian Liver Foundation has recommended a national study of HCV prevalence that adequately samples these communities (4).

The present model has several limitations. The model does not consider the potential for continued disease progression in cases cured of HCV infection based on current treatments. Some individuals with advanced liver disease are at risk for progressive liver disease after achieving SVR, albeit at a slower rate $(50,51)$. The potential contribution of extrahepatic manifestations of HCV infection on all-cause mortality was also not included in the model, potentially leading to an underestimate of mortality among viremic cases (52). As a result, the projected numbers of decompensated cirrhosis and HCC may be overestimated. Finally, we have not addressed the costs of current antiviral therapies and testing costs, nor have we accounted for indirect medical costs such as reduced productivity and quality of life, which have a significant impact on individuals infected with HCV.

\section{CONCLUSION}

The present analysis demonstrated that overall HCV prevalence in Canada is decreasing; however, the prevalence of advanced liver disease and HCV-related costs will continue to increase as the infected population ages. These results will facilitate disease forecasting, resource planning and the development of rational management strategies for $\mathrm{HCV}$ in Canada. To reduce the future burden and costs of chronic hepatitis $\mathrm{C}$, there is an urgent need to enhance case identification and optimize the utilization of antiviral therapies. Provincial organizations and the Canadian Liver Foundation have identified these strategies, especially among high-risk populations, as important priorities (53-57). Hopefully, higher rates of diagnosis during early disease stages, coupled with new treatment regimens with higher SVR rates and improved tolerability, will help stem the imminent tide of $\mathrm{HCV}$-related morbidity and mortality.

DISCLOSURES: This study was supported by an unrestricted grant from Gilead Sciences Canada, manufacturers of antiviral therapies for HCV. The sponsor had no input into the design, conduct or analysis of this study, drafting of the manuscript, nor the decision to submit the manuscript for publication. Robert Myers has received research support, consulting, and/or speaking fees from Gilead, Merck, Roche, Vertex, Janssen, BoehringerIngelheim, Idenix, Abbvie and GlaxoSmithKline. Mel Krajden has received research support from Roche, Siemens, Hologic (Gen-Probe), Merck, and Boehringer-Ingelheim. Marc Bilodeau has received research support, consulting, and/or speaking fees from Gilead, Merck, Novartis, Vertex, GlaxoSmithKline, Synageva, Astellas and Bayer. Kelly Kaita has received consulting and/or speaking fees from Gilead, Merck, Roche, Vertex, Bristol-Myers Squibb, Boehringer-Ingelheim, Janssen and Abbvie. Paul Marotta has research support, consulting, and/or speaking fees from Gilead, Merck, Vertex, Boehringer-Ingelheim, Astellas, Abbvie and Novartis. Alnoor Ramji has received research support, consulting, and/or speaking fees from Gilead, Merck, Roche, Vertex, Janssen, BoehringerIngelheim, Novartis, Abbvie, Bristol-Myers Squibb and GlaxoSmithKline. Morris Sherman has received consulting and/or speaking fees from Gilead, Vertex, Merck, Janssen, Abbvie and Boehringer-Ingelheim. Homie Razavi and Chris Estes are employees of the Center for Disease Analysis (CDA).

\section{REFERENCES}

1. Mohd Hanafiah K, Groeger J, Flaxman AD, Wiersma ST. Global epidemiology of hepatitis $\mathrm{C}$ virus infection: New estimates of agespecific antibody to HCV seroprevalence. Hepatology 2013;57:1333-42.

2. Trubnikov M. Developing estimates of prevalent and undiagnosed HCV infection in Canada in 2011. <www youtube com/watch?v=2 34ru9AFA6U\& list=PLy0zwf7_pKrXSh9bx6XxznPv65S44nN6q\&n oredirect $=1$ 2014 $>$ (Accessed February 9, 2014).

3. Remis RS. Modelling the incidence and prevalence of hepatitis $\mathrm{C}$ infection and its sequelae in Canada, 2007: Final report.

Community Acquired Infections Division, Centre for Communicable Diseases and Infection Control, Public Health Agency of Canada 2009. < http://epe.lac-bac.gc.ca/100/200/301/ phac-aspc/modeling_hepatis_c_infection-e/HP40-39-2009E.pdf> (Accessed February 9, 2014).

4. Canadian Liver Foundation. Liver disease in Canada - a crisis in the making. < www liver ca/support-liver-foundation/advocate/ Liver_Disease_in_Canada_Report aspx 2013> (Accessed February 9, 2014).

5. Zou S, Tepper M, El Saadany S. Prediction of hepatitis $\mathrm{C}$ burden in Canada. Can J Gastroenterol 2000;14:575-80.

6. Myers RP, Liu M, Shaheen AA. The burden of hepatitis $C$ virus infection is growing: A Canadian population-based study of hospitalizations from 1994 to 2004. Can J Gastroenterol 2008;22:381-7.

7. Kershenobich D, Razavi HA, Cooper CL, et al. Applying a system approach to forecast the total hepatitis $\mathrm{C}$ virus-infected population size: Model validation using US data. Liver Int

2011;31(Suppl 2):4-17. 
8. Razavi H, Elkhoury AC, Elbasha E, et al. Chronic hepatitis C virus $(\mathrm{HCV})$ disease burden and cost in the United States. Hepatology 2013;57:2164-70.

9. United Nations Dept of Economic and Social Affairs.Population Division (2011). World population prospects: The 2010 revision, Volume I: Comprehensive tables. ST/ESA/SER.A/313.2011 $<$ http://esa.un.org/wpp/Documentation/pdf/WPP2010_Volume-I_ Comprehensive-Tables.pdf $>$ (Accessed February 9, 2014).

10. Public Health Agency of Canada. Hepatitis C in Canada: $2005-$ 2010 surveillance report. 2012 <www.phac-aspc.gc.ca/sti-its-survepi/hepc/surv-eng.php > (Accessed February 9, 2014).

11. Seeff LB. Natural history of chronic hepatitis C. Hepatology 2002;36:S35-S46.

12. Antonishyn NA, Ast VM, McDonald RR, et al. Rapid genotyping of hepatitis $\mathrm{C}$ virus by primer-specific extension analysis. J Clin Microbiol 2005;43:5158-63.

13. Statistics Canada. Seroprevalence of hepatitis B and C virus infections: Results from the 2007 to 2009 and 2009 to 2011 Canadian Health Measures Survey. Nov 202013 <www.statcan.gc. ca/pub/82-003-x/2013011/article/11876-eng.htm> (Accessed February 9, 2014).

14. Public Health Agency of Canada. Notifiable Diseases Online.2005 1991-2004 <http://dsol-smed.hc-sc.gc.ca/dsol-smed/ndis/c_inda-eng. php $>$ (Accessed February 9, 2014).

15. Evon DM, Verma A, Dougherty KA, et al. High deferral rates and poorer treatment outcomes for HCV patients with psychiatric and substance use comorbidities. Dig Dis Sci 2007;52:3251-8.

16. Morrill JA, Shrestha M, Grant RW. Barriers to the treatment of hepatitis C. Patient, provider, and system factors. J Gen Intern Med 2005;20:754-8

17. IMS Health. IMS Health MIDAS Data. IMS Health Jan 12013 <www.imshealth.com/portal/site/ims/menuitem.edb2b81823f67dab4 1d84b903208c22a/?vgnextoid=4475e3de7e390310VgnVCM100000 7f8c2ca2RCRD> (Accessed February 9, 2014).

18. Myers RP, Ramji A, Bilodeau M, Wong S, Feld JJ. An update on the management of hepatitis C: Consensus guidelines from the Canadian Association for the Study of the Liver.

Can J Gastroenterol 2012;26:359-75.

19. Seeff LB, Hollinger FB, Alter HJ, et al. Long-term mortality and morbidity of transfusion-associated non- $\mathrm{A}$, non- $\mathrm{B}$, and type $\mathrm{C}$ hepatitis: A National Heart, Lung, and Blood Institute collaborative study. Hepatology 2001;33:455-63.

20. Deuffic-Burban S, Deltenre P, Buti M, et al. Predicted effects of treatment for HCV infection vary among European countries. Gastroenterology 2012;143:974-85.

21. Alter MJ, Margolis HS, Krawczynski K, et al. The natural history of community-acquired hepatitis $\mathrm{C}$ in the United States. The Sentinel Counties Chronic non-A, non-B Hepatitis Study Team. N Engl J Med 1992;327:1899-905.

22. Thomas DL, Seeff LB. Natural history of hepatitis C. Clin Liver Dis 2005;9:383-98

23. Villano SA, Vlahov D, Nelson KE, Cohn S, Thomas DL. Persistence of viremia and the importance of long-term follow-up after acute hepatitis C infection. Hepatology 1999;29:908-14.

24. Thein HH, Yi Q, Dore GJ, Krahn MD. Estimation of stage-specific fibrosis progression rates in chronic hepatitis $\mathrm{C}$ virus infection: A meta-analysis and meta-regression. Hepatology 2008;48:418-31.

25. Bennett WG, Inoue Y, Beck JR, Wong JB, Pauker SG, Davis GL. Estimates of the cost-effectiveness of a single course of interferonalpha $2 \mathrm{~b}$ in patients with histologically mild chronic hepatitis C. Ann Intern Med 1997;127:855-65.

26. Bernfort L, Sennfalt K, Reichard O. Cost-effectiveness of peginterferon alfa- $2 \mathrm{~b}$ in combination with ribavirin as initial treatment for chronic hepatitis C in Sweden. Scand J Infect Dis 2006;38:497-505.

27. Younossi ZM, Singer ME, McHutchison JG, Shermock KM. Cost effectiveness of interferon alpha2b combined with ribavirin for the treatment of chronic hepatitis C. Hepatology 1999;30:1318-24.

28. Canadian Institute for Health Information. e-Statistics report on transplant, waiting list and donor statistics. $2012<$ www.cihi.ca/ CIHI-ext-portal/internet/en/document/types + of + care/ specialized+services/organ+replacements/report_stats2012> (Accessed February 9, 2014).

29. Canadian Institute for Health Information. Canadian organ replacement register annual report: Treatment of end-stage organ failure in Canada, 2001 to 2010. 2011.
30. Organ Procurement and Transplantation Network (OPTN). 2009 OPTN/SRTR annual report 1999-2008: Table 9.15a. Unadjusted patient survival by year of transplant at 3 months, 1 year, 3 years, 5 years and 10 years, deceased donor liver transplants. 2009 Annual report of the U S Organ Procurement and Transplantation Network and the Scientific Registry of Transplant Recipients: Transplant data 1999-2008 2009 <www.ustransplant.org/annual_reports/ current/915a_li.htm $>$ (Accessed February 9, 2014).

31. Organ Procurement and Transplantation Network (OPTN). National Data. Health Resources and Services Administration, U.S. Department of Health \& Human Services; 2013.

32. University of California, Berkeley, Mack Planck Institute for Demographic Research. Human Mortality Database. <www.mortality.org> (Accessed February 9, 2014).

33. Engstrom A, Adamsson C, Allebeck P, Rydberg U. Mortality in patients with substance abuse: A follow-up in Stockholm County, 1973-1984. Int J Addict 1991;26:91-106.

34. Frischer M, Goldberg D, Rahman M, Berney L. Mortality and survival among a cohort of drug injectors in Glasgow, 1982-1994. Addiction 1997;92:419-27.

35. Hickman M, Carnwath Z, Madden P, et al. Drug-related mortality and fatal overdose risk: Pilot cohort study of heroin users recruited from specialist drug treatment sites in London. J Urban Health 2003;80:274-87.

36. Oppenheimer E, Tobutt C, Taylor C, Andrew T. Death and survival in a cohort of heroin addicts from London clinics: A 22-year follow-up study. Addiction 1994;89:1299-308.

37. Perucci CA, Davoli M, Rapiti E, Abeni DD, Forastiere F. Mortality of intravenous drug users in Rome: A cohort study. Am J Public Health 1991;81:1307-10.

38. Bjornaas MA, Bekken AS, Ojlert A, et al. A 20-year prospective study of mortality and causes of death among hospitalized opioid addicts in Oslo. BMC Psychiatry 2008;8:8.

39. Kamper-Jorgensen M, Ahlgren M, Rostgaard K, et al. Survival after blood transfusion. Transfusion 2008;48:2577-84.

40. El Saadany S, Coyle D, Giulivi A, Afzal M. Economic burden of hepatitis $\mathrm{C}$ in Canada and the potential impact of prevention. Results from a disease model. Eur J Health Econ 2005;6:159-65.

41. Thein HH, Isaranuwatchai W, Campitelli MA, et al. Health care costs associated with hepatocellular carcinoma: A population-based study. Hepatology 2013;58:1375-84.

42. Taylor MC, Greig PD, Detsky AS, McLeod RS, Abdoh A, Krahn MD. Factors associated with the high cost of liver transplantation in adults. Can J Surg 2002;45:425-34.

43. Statistics Canada. Consumer Price Index, health and personal care (Canada). <www.statcan.gc.ca/tables-tableaux/sum-som/101/cst01/ econ161a-eng.htm> (Accessed February 9, 2014).

44. Kwong JC, Crowcroft NS, Campitelli MA, et al. Ontario Burden of Infectious Disease Study (ONBOIDS): An OAHPP/ICES Report. Toronto, CA: Ontario Agency for Health Protection and Promotion; Institute for Clinical Evaluative Sciences; 2010.

45. Shah HA, Heathcote J, Feld JJ. A Canadian screening program for hepatitis C: Is now the time? CMAJ 2013;185:1325-8.

46. Canadian Liver Foundation. Hepatitis C Testing. $2012<$ www.liver. ca/support-liver-foundation/advocate/clf-position-statements/ hepatitis_C_testing.aspx $>$ (Accessed February 9, 2014).

47. McAdam-Marx C, McGarry LJ, Hane CA, Biskupiak J, Deniz B, Brixner DI. All-cause and incremental per patient per year cost associated with chronic hepatitis $\mathrm{C}$ virus and associated liver complications in the United States: A managed care perspective. J Manag Care Pharm 2011;17:531-46.

48. Bayoumi AM, Zaric GS. The cost-effectiveness of Vancouver's supervised injection facility. CMAJ 2008;179:1143-51.

49. Hellard M, Doyle JS, Sacks-Davis R, Thompson AJ, McBryde E. Eradication of hepatitis $\mathrm{C}$ infection: The importance of targeting people who inject drugs. Hepatology 2014;59:366-9.

50. Aleman S, Rahbin N, Weiland O, et al. A risk for hepatocellular carcinoma persists long-term after sustained virologic response in patients with hepatitis C-associated liver cirrhosis. Clin Infect Dis 2013;57:230-6.

51. Singal AG, Volk ML, Jensen D, Di Bisceglie AM, Schoenfeld PS. A sustained viral response is associated with reduced liver-related morbidity and mortality in patients with hepatitis $\mathrm{C}$ virus. Clin Gastroenterol Hepatol 2010;8:280-8.

52. Yu A, Spinelli JJ, Cook DA, Buxton JA, Krajden M. Mortality among British Columbians testing for hepatitis C antibody. BMC Public Health 2013;13:291. 
53. A proposed strategy to address hepatitis C in Ontario 2009-2014. Ontario Hepatitis C Task Force; 2009.

54. British Columbia Ministry of Health. Healthy Pathways Forward: A Strategic Integrated Approach to Viral Hepatitis in BC. 2007.

55. Government of Alberta, Alberta Health and Wellness -Community and Population Health Division. Alberta Sexually Transmitted Infections and Blood Borne Pathogens Strategy and Action Plan: 2011-2016. 2011.

56. Santé et Services Sociaux Quebec. [Quebec's strategy to fight against HIV and AIDS, HCV and sexually transmitted infections] Stratégie québécoise de lutte contre l'infection par le VIH et le sida, l'infection par le VHC et les infections transmissibles sexuellement: Orientations 2003-2009. 2004.
57. Canadian Liver Foundation. Eliminating Hepatitis C in Canada. $2013<$ www.liver.ca/support-liver-foundation/advocate/clf-positionstatements/Eliminating_hep_C_in_Canada.aspx $>$ (Accessed February 9, 2014).

58. Ries LAG, Young GL, Keel GE, Eisner MP, Lin, YD Horner, MJ. SEER survival monograph: Cancer survival among adults: U.S. SEER program, 1988-2001, patient and tumor characteristics National Cancer Institute, SEER Program; 2007. NIH Pub. No. 07-6215.

59. Thein HH, Isaranuwatchai W, Campitelli MA, et al. Health care costs associated with hepatocellular carcinoma: A population-based study. Hepatology 2013;58:1375-84. 


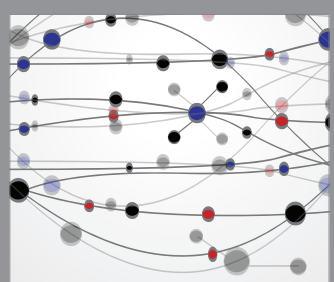

The Scientific World Journal
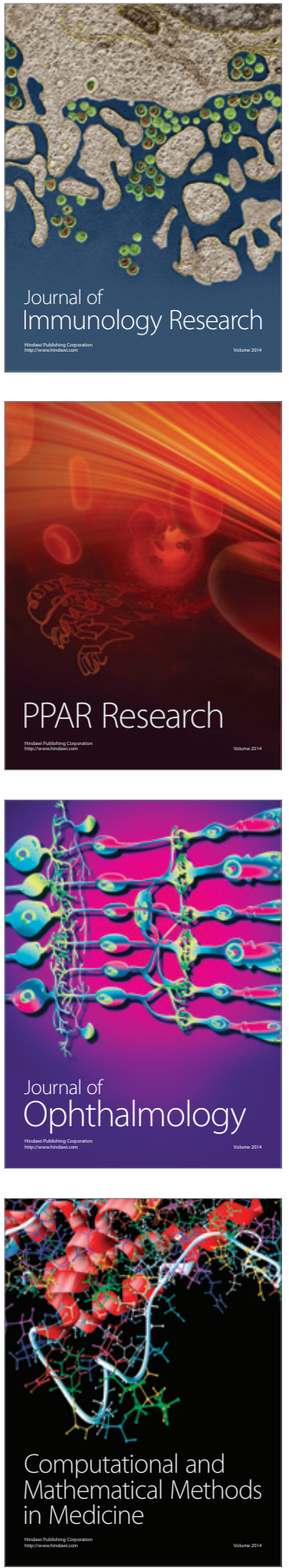

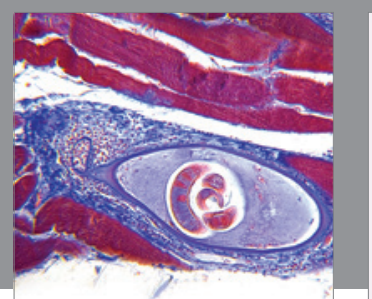

Gastroenterology Research and Practice

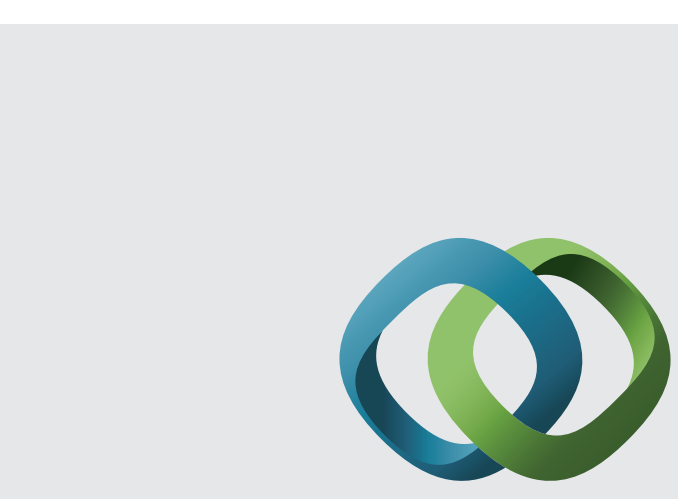

\section{Hindawi}

Submit your manuscripts at

http://www.hindawi.com
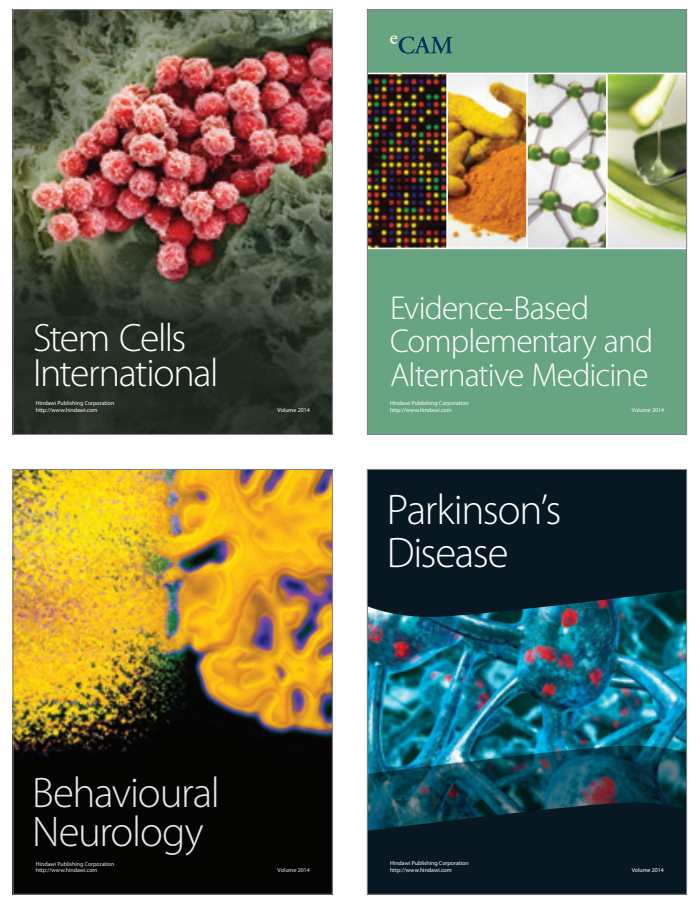
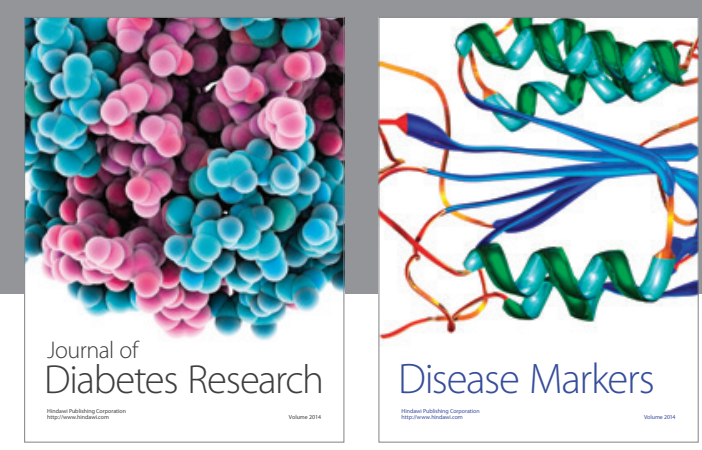

Disease Markers
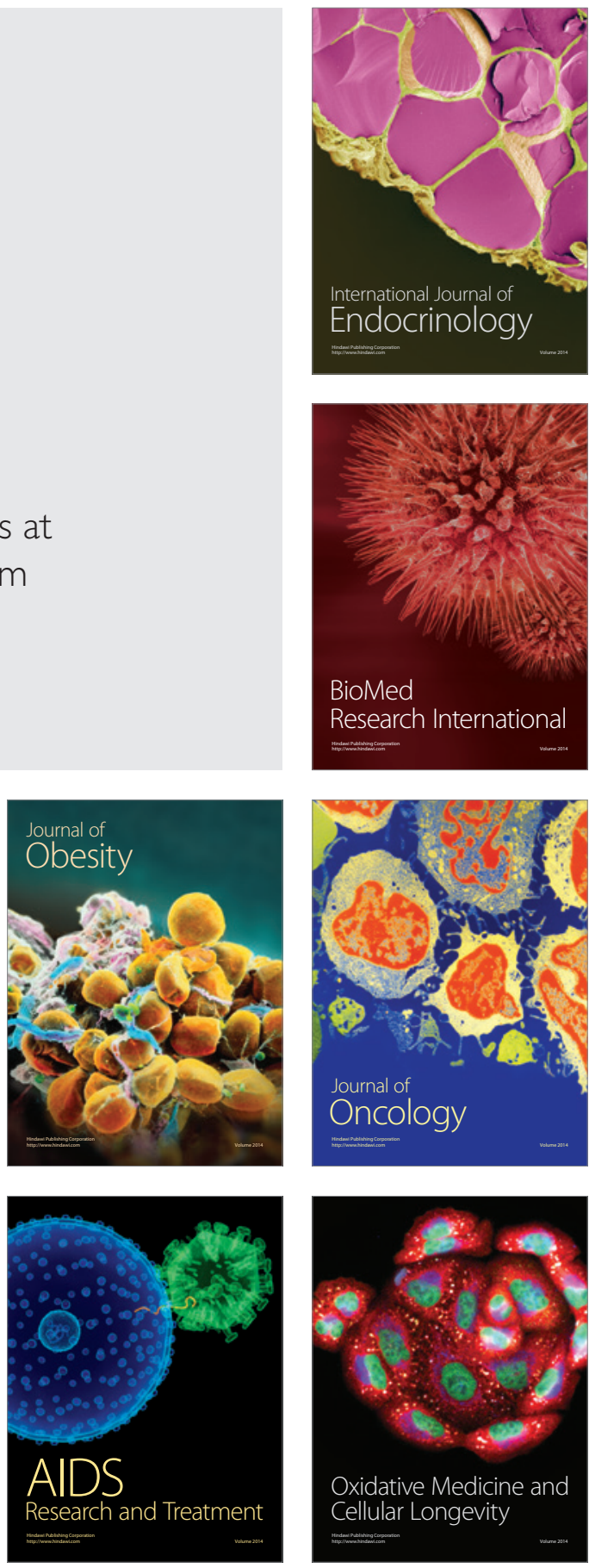